\title{
A Community Engagement Method to Design Patient Engagement Materials for Cardiovascular Health
}

Aimee F. English, $M D^{1}$

L. Miriam Dickinson, $P b D^{1}$

Linda Zittleman, MSPH ${ }^{1}$

Donald E. Nease, Jr, MD

Alisha Herrick, MPH ${ }^{2}$

Jobn M. Westfall, MD, MPH

Matthew J. Simpson, MD, MPH

Douglas H. Fernald, MA ${ }^{1}$

Robert L. Rbyne, $M D^{2}$

W. Perry Dickinson, $M D^{1}$

'Department of Family Medicine,

University of Colorado School of Medicine,

Aurora, Colorado

${ }^{2}$ Department of Family Medicine,

University of New Mexico, Albuquerque,

New Mexico

Conflicts of interest: authors report none.

\section{CORRESPONDING AUTHOR}

Aimee F. English, MD

3055 Roslyn St, Ste 100

Denver, CO 80238

aimee.english@ucdenver.edu

\begin{abstract}
PURPOSE EvidenceNOW Southwest is a cluster-randomized trial evaluating the differential impact on cardiovascular disease (CVD) care of engaging patients and communities in practice transformation in addition to standard practice facilitation support. The trial included development of locally tailored CVD patient engagement materials through Boot Camp Translation (BCT), a community engagement process that occurred before practice recruitment but after cluster randomization.
\end{abstract}

METHODS We introduce a cluster randomization method performed before recruitment of small to medium-size primary care practices in Colorado and New Mexico, which allowed for balanced study arms while minimizing contamination. Engagement materials for the enhanced study arm were developed by means of $\mathrm{BCT}$, which included community members, practice members, and public health professionals from (1) metropolitan Denver, (2) rural northeast Colorado, (3) Albuquerque, and (4) rural southeast New Mexico. Outcome measures were messages and materials from BCTs and population characteristics of study arms after using geographic-based covariate constrained randomization.

RESULTS The 4 BCTs' messages and materials developed by the BCT groups uniquely reflected each community and ranged from family or spiritual values to early prevention or adding relevance to CVD risk. The geographic-based covariate of a cluster randomization method constrained randomization-assigned regions to study arms, allowing BCTs to precede practice recruitment, reduce contamination, and balance populations.

CONCLUSIONS Cluster-randomized trials with community-based interventions present study design and implementation challenges. The BCTs elicited unique contextual messages and materials, suggesting that interventions designed to help primary care practices decrease CVD risk may not be one size fits all.

Ann Fam Med 2018;16(Suppl 1)S58-S64. https://doi.org/10.1370/afm.2173.

\section{INTRODUCTION}

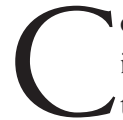
ommunities, patients, and families can play a role in practice improvement, and there have been increasing calls to engage them in practice transformation efforts, including by the Institute of Medicine, ${ }^{1}$ Patient-Centered Medical Home standards, ${ }^{2}$ and the requirements of the Centers for Medicare \& Medicaid Services program Comprehensive Primary Care Plus. ${ }^{3}$ The benefits of engaging patients and families in the care of individual patients is well established. . $^{411}$ The outcomes of engaging communities, patients, and families at the practice level, however, are less well documented. ${ }^{12,13}$ The EvidenceNOW: Advancing Heart Health in Primary Care is an Agency for Healthcare Research and Quality grant initiative dedicated to using the latest evidence to improve the heart health of Americans. EvidenceNOW Southwest is a regional cooperative that has sought to test the differential impacts on cardiovascular disease (CVD) of interventions focused on patient, family, and community engagement to standard practice transformation approaches. 
In EvidenceNOW Southwest, enhanced-arm practices received practice facilitation plus additional support to engage patients and families in practice transformation. These practices were able to order free heart health materials that were developed through a community engagement method known as Boot Camp Translation (BCT) in 4 communities within the enhanced-arm geographic regions (2 in Colorado, 2 in New Mexico). Community members and health professionals worked together to learn about complex health topics and national guidelines so the community-academic partnership could then translate those messages into ones that are relevant and meaningful to their local community. ${ }^{14,15}$ The process aimed not to seek perfect community representation but rather to harness local expertise to create locally tailored products and messaging.

There were 3 major study design challenges in our randomized trial to evaluate the impact of a community engagement method on practices. First, cluster randomized trials, commonly used in practice-based studies that involve randomization at the level of the practice, ${ }_{1}^{16-18}$ incur risk of contamination if used with interventions occurring at the community level where there might be standard and enhanced-arm practices in close proximity. Second, in our study, communities in which the community engagement method occurred needed to be identified before practice recruitment. In this case, BCT communities had to be selected so that materials would be ready for use by the enhancedarm practices at the start of the intervention period. A potential solution to these problems was to define geographic regions as the units for randomization. This raises the third issue, however, of potentially having unbalanced study arms. Randomization methods that improve study arm balance in terms of underlying populations and regional differences are essential for community-based trials. ${ }^{19}$

We describe (1) the results of $4 \mathrm{BCTs}$ in unique communities across diverse regions of Colorado and New Mexico and (2) approaches to study design challenges for a randomized trial evaluating the effect of patient, family, and community engagement on practice transformation and cardiovascular risk reduction.

\section{METHODS}

\section{Study Setting}

The EvidenceNOW Southwest Cooperative is a collaborative effort between Colorado and New Mexico and covers the diverse geographic and cultural regions across both states. It is one of 7 regional cooperatives funded by the Agency for Healthcare Research and Quality to help small and medium-size primary care practices across the country use the latest evidence to improve cardiovascular health. The project was approved by both the Colorado Multiple Institutional Review Board and the University of New Mexico Human Research Protections Office.

\section{EvidenceNOW Southwest Intervention}

Practices within both the standard and enhanced arms received the following: ongoing practice transformation support from a trained practice facilitator, support from a clinical health information technology advisor, connection to a regional health extension agent (regional health connector in Colorado, health extension rural officer or HERO in New Mexico), and opportunity to attend biannual collaborative learning sessions in which knowledge is shared across practice teams (also attended by practice facilitators, regional health connectors/health extension regional officers, and clinical health information technology advisors).

Enhanced-arm practices received additional support to increase patient, family, and community engagement within their practice transformation efforts through the use of BCT materials and support to engage patients and families in practice transformation efforts. Because CVD guidelines are relatively inaccessible to the general population owing to medical complexity and jargon, the intention of the BCTs was to allow communities to create materials to provide CVD education in a way that may be more relevant to enhanced-arm communities and practices. Throughout the project, printed BCT materials from all 4 BCTs were available for order at no cost to all enhanced practices (regardless of their geographic proximity to the BCT). Processes and outcomes related to utilization of BCT materials are being tracked and will be reported in a later publication after the completion of the study.

\section{EvidenceNOW Southwest Study Design}

Because of the intent to implement the community engagement method (ie, BCT) at the community and regional level, randomization at the level of the primary care practice was not feasible. There was concern about the strong potential for contamination between study arms if standard intervention practices were located in regions from which BCT participants would be recruited and their products would be promoted. Additionally, because the timeline of the study required beginning $\mathrm{BCT}$ activities before actual practice recruitment and enrollment, it was necessary to select regions for the BCTs that would include only those practices from the enhanced intervention study arm. We therefore defined geographic regions (ie, cluster) as the unit of randomization. Finally, regional differences across 2 states in underlying population 
characteristics were considerable, and simple randomization could result in unbalanced study arms, requiring approaches for achieving balanced study arms in terms of the underlying populations and resources.

\section{Covariate Constrained Randomization}

Because EvidenceNOW Southwest is a cooperative study across 2 states, and local knowledge about geographic regions was key to informing design decisions, randomization was carried out separately in each state.

In Colorado, we used data from the most recent US Census, Health Landscapes, the Cold Spotting Colorado project, ${ }^{20}$ and local knowledge about geography and proximity to health care services to define 26 regions consisting of 1 or more counties that are roughly equivalent to the Colorado Health Statistics Regions. These were split into 2 strata for randomization: (1) Front Range and Eastern Plains and (2) mountains and Western Slope. Within each stratum, we used covariate constrained randomization ${ }^{21,22}$ to achieve balanced study arms with respect to population and health resource characteristics. Variables included total population of the region, average county population, percentage at or below poverty level, median income, percentage white, percentage Hispanic, number of primary care physicians per 10,000 population, number of physician assistants/nurse practitioners per 10,000 population, unemployment rate, and number of uninsured adults aged 18 to 64 years old. The goal was to define clusters as groups of counties that were relatively homogeneous and large enough to facilitate implementation of BCTs without undue risk of contamination into the standard intervention counties, as well as to achieve balanced study arms on underlying population characteristics.

Table 1. Population Characteristics of Standard and Enhanced Regions

\begin{tabular}{|c|c|c|}
\hline Characteristic & Greeley, Coloradoa & Denver, Colorado ${ }^{b}$ \\
\hline $\begin{array}{l}\text { Community } \\
\text { description }\end{array}$ & $\begin{array}{l}\text { Largely rural agricultural communities } \\
\text { Population } \sim 75,000 \\
\text { Approximately } 30 \% \text { Hispanic } \\
\text { Lower average income and higher } \\
\text { rates of poverty than rest of state }\end{array}$ & $\begin{array}{l}\text { Population }>3 \text { million } \\
\text { Among fastest growing urban centers } \\
\text { in the United States } \\
80 \% \text { White with approximately } 30 \% \\
\text { of its residents identifying as Latino }\end{array}$ \\
\hline $\begin{array}{c}\text { Themes and } \\
\text { messages }\end{array}$ & $\begin{array}{l}\text { Early intervention is key, emphasized } \\
\text { knowing personal heart health } \\
\text { numbers, including blood pressure, } \\
\text { cholesterol, 10-yr ASCVD risk } \\
\text { Track health data over time } \\
\text { Provide context around CVD risk } \\
\text { (What does } 7 \% \text { risk mean for me?) } \\
\text { Wanted a conversation starter for } \\
\text { patient to discuss CVD risk with } \\
\text { health professionals }\end{array}$ & $\begin{array}{l}\text { You only have } 1 \text { heart-your life } \\
\text { depends on it } \\
\text { Know your risk, even if you feel fine } \\
\text { Act now to lower your risk } \\
\text { Wanted to design products for any } \\
\text { age-group } \\
\text { Use brochure to grab attention and } \\
\text { dig deeper into actions with the } \\
\text { Risk Factor Check List }\end{array}$ \\
\hline
\end{tabular}

Product description

Example product

$A B C S=$ aspirin use, blood pressure, cholesterol management, smoking cessation; $A S C V D=$ atherosclerotic cardiovascular disease; $\mathrm{BMI}=$ body mass index $; \mathrm{CVD}=$ cardiovascular disease.

a Northeast Colorado.

b Denver and Golden, Colorado.

'Parts of Albuquerque and unincorporated San Bernalillo county. 


\section{Hobbs, New Mexico}

Among eastern-most counties in New Mexico.

Population $\sim 35,000$

Highest percentage of African American population in the state

Describe themselves as a part of West Texas, because geographically they are closer to

Texas than most other places in New Mexico

Oil and gas are the main sources of income in the region

A clean spiritual life requires a healthy physical life-complete spiritual, physical, and mental health are needed to be whole

Focus on what we can control, not what we can't (eg, family history)

Heart disease does not discriminate; no matter one's heritage, ethnicity, religion, etc, we are all at risk

Many members from faith-based community; our bodies are worthy of care

Taking care of health is actually cheaper ("sale") than consequences of CVD event

Encouraged implementation in community, but also in practice setting

Big sign saying "Big Sale!" with information about CVD risk reduction

Hand-held, heart-shaped fan with "We are all different but we all have heart-heart disease does not discriminate."

Magnet that reads "Our bodies are miracles... but we have to treat them that way!"

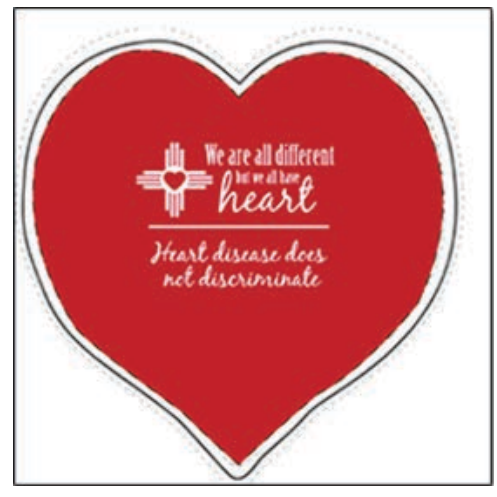

\section{South Valley, Albuquerque, New Mexico}

Urban/rural mix; high-density areas are intermingled with agricultural land

Population $\sim 40,000$

Predominantly Hispanic, with many recent immigrants from Latin America

Messages aim to elicit a feeling -think about family, love, prevention in a multi-generational sense

Educate ALL ages and get the entire family involved-youth can help the family change and adults and seniors want to be around for their family

Focus on Latino communities

Prevent second chances. Don't wait for something to happen to take action

"Know your numbers before your 'check heart' light comes on"

Implement in community, but also in practice setting

Attention to the need for materials to be in both Spanish and English

Trifold brochure informational brochure titled "Prevent second chances"

One-page handout with key heart health numbers in the form on the image of a car dashboard Informational poster with a picture of a family Grocery bag that says "Cuídalo" and displays the ABCS

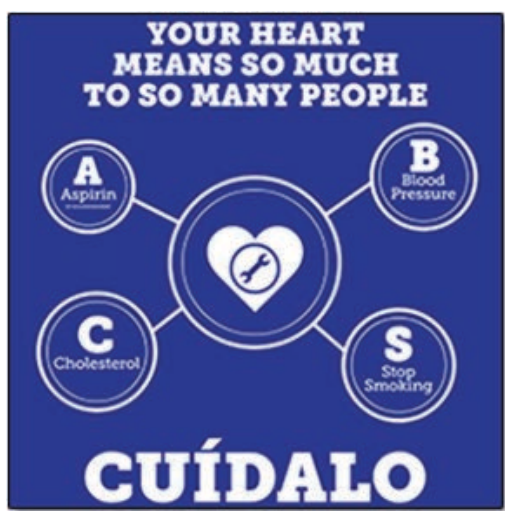

ducted, 2 in each state, with regions selected to represent diverse populations. The limited number of BCTs conducted was due to resource limitations to conduct the BCT and produce the resulting materials. Each region in which a BCT occurred had been randomized to the enhanced study arm.

$\mathrm{BCT}$ s were conducted in Hobbs, New Mexico, the South Valley region of Albuquerque, northeast Colorado, and the Denver metropolitan area.

These regions differed in ethnic diversity, industry, population, and rural-urban mix. Individual community descriptions can be found in Table 1.

\section{BCT Process}

The goal of the EvidenceNOW Southwest BCT was to take evidence-based CVD prevention strategies and translate that content into messaging and materials that are relevant and understandable for community members. Through participation in BCT, community members become better prepared to discuss CVD within their communities, and participants developed unique materials for practices and other community agencies to use for patient/community engagement. ${ }^{14,15} \mathrm{BCT}$ participants also included practice clinicians and staff, as well as local public health officers, to ensure that the messages and materials would be relevant for use by the practices and local public health.

Each BCT began with an allday kickoff retreat. For one-half

ized regions within each group, resulting in an even number of regions (8 each) per study arm.

\section{EvidenceNOW Southwest BCT Communities}

Once all regions of both states had been assigned to enhanced or standard intervention arms, the regions for the BCTs were identified. Four BCTs were con- of the retreat, a medical expert presented the current evidence and guidelines for the prevention of CVD, specifically focusing on the ABCS (aspirin use, blood pressure control, cholesterol management, smoking cessation) guidelines. Although each BCT had a different medical expert, presenters used the same set of informational slides across all presentations. After the 
presentation, the remaining retreat time was spent brainstorming answers to (1) what does our community need to know about CVD prevention, and (2) what actions do we want people to take around CVD prevention?

After the kickoff retreat, each group had a series of 4 to 6 conference calls interspersed with 3 to 4 in-person meetings over a 6 - to 9-month period during which they continued to refine key messages and products. Through these follow-up sessions, each group created a set of locally relevant actionable messages and materials.

\section{Recruitment of BCT Participants}

Within each state, participants were recruited through use of different organizations, based on which organizations would have better ties with the community. As a result, in New Mexico, with its well-established health extension system, the health extension rural officers recruited participants. In Colorado, with its long history of community-engaged research, practicebased research networks recruited participants. Participants were selected based on their availability to participate for the duration of the BCT, their ability to engage and be present, their interest in the topic, and the absence of a hidden agenda.

\section{RESULTS}

Colorado and New Mexico have a combined population of approximately 7.3 million. Sociodemographic characteristics of the 2 states show considerable diversity in terms of ethnicity, education, population density, disease burden, and health care resources. Covariateconstrained randomization procedures resulted in reasonably well-balanced study arms with respect to key regional population characteristics that might affect study implementation or outcomes (Table 2).

\section{BCT Partners}

Community members with varying amounts of experience with CVD were included in the BCT. They had differing skill sets and expertise, as shown in Table 3.

\section{BCT Key Messages and Materials}

Each BCT was tasked with translating evidence-based cardiovascular risk-reduction strategies into messaging and materials relevant to their local communities to be used by practices for patient engagement. The resulting materials varied considerably from one BCT to another.

The Hobbs, New Mexico, BCT included messaging about spirituality and universality of risk regardless of background, producing 3 products, including a heart-shaped fan that could be taken to football games (Table 1). In the South Valley region of New Mexico, messages aimed to elicit feelings around the importance of and responsibility to Latino communities and family. Prevention was a key message, particularly in the context of family. They produced 4 products including a grocery bag with "Cuídalo" printed on it (translation: "Take care of it"). It was culturally important to the participants that this bag be in Spanglish, a combination of Spanish and English. The northeast Colorado BCT emphasized early intervention but focused heavily on numbers (eg, individual CVD risk score, cholesterol levels) and putting those numbers into an easily interpretable context. The group created 2 products, including a heart chart, a personal tracking tool for recording blood pressure, cholesterol, body mass index, and 10 -year risk of CVD similar to pediatric growth curves to provide comparison to normal age-related risk over time. The metropolitan Denver BCT also sought to raise awareness and empower patients to act now to lower their risk. They produced 3 products, including a risk factor checklist with questions prompting patients to think about their own CVD risk factors. Table 1 displays a complete description of key messages and products.

\section{Practice Recruitment}

After the BCTs were completed, a total of 211 primary care practices were recruited and enrolled from Colorado $(\mathrm{n}=158)$ and New Mexico $(\mathrm{n}=53)$ across the diverse geographic regions of the 2 states. BCT mate- 


\section{New Mexico}

\begin{tabular}{cccc}
\multicolumn{2}{c}{ Standard $(\mathbf{n}=\mathbf{8})$} & \multicolumn{2}{c}{ Enhanced $\mathbf{( n = 8 )}$} \\
\hline Mean (SD) & Min/Max & Mean (SD) & Min/Max \\
\hline $39,872(38,989)$ & $1,975 / 145,400$ & $97,866(174,455)$ & $687 / 667,092$ \\
$40.3(18.6)$ & $10.2 / 75.3$ & $39.9(12.8)$ & $18.1 / 67.8$ \\
$43.5(18.3)$ & $13.6 / 81.7$ & $48.7(14.5)$ & $19.2 / 76.9$ \\
$21.7(6.4)$ & $4.4 / 35.0$ & $19.9(5.2)$ & $11.9 / 28.6$ \\
$8.0(3.2)$ & $4.2 / 19.0$ & $7.0(1.9)$ & $4.5 / 10.2$ \\
$6,547(6,639)$ & $354 / 24,747$ & $16,060(27,611)$ & $98 / 103,316$ \\
$41,228(16,715)$ & $28,275 / 106,686$ & $39,207(7,737)$ & $27,430 / 50,694$ \\
$3.9(2.3)$ & $0.0 / 9.2$ & $3.7(1.9)$ & $0.0 / 6.7$ \\
$7.9(3.6)$ & $2.1 / 18.5$ & $6.7(4.0)$ & $0.0 / 14.4$ \\
\hline
\end{tabular}

rials were available only to practices in the enhanced intervention arm until study completion.

\section{DISCUSSION}

Designing a randomized control trial involving community engagement is especially challenging across 2 states with diverse populations, with the need to minimize contamination and to ensure that key population groups are included in the community engagement activities. We defined clusters as geographic regions through a combination of census data and knowledge of local communities, and we used covariate-constrained randomization procedures to allocate regions to balanced study arms before initiating the community engagement method and recruiting practices. By minimizing overall differences between study arms, this procedure enriches heterogeneity within study arms, thus ensuring representation of diverse populations in both study arms.

Unique BCT messages and materials were produced in the 4 selected communities for use by enhanced intervention practices throughout the EvidenceNOW Southwest project. Messages ranged from family values and spirituality to early prevention and identifying a need for context of CVD risk. Materials written in English were translated into Spanish, and their form ranged from brochures to patient-held health records to novelties, such as fans and grocery bags. Though products from each site were unique-reflecting the key features each community group believed would resonate with their local audiences-each site incorporated the ABCS into at least 1 product. Also, a sense of urgency and importance that heart disease is preventable was observed across all sites. The diverse products were reflective of cultural differences and varying priorities across the regions. We believe tailoring patient engagement materials to specific communities will enhance primary care practices' capacity to improve evidence-based care by making the messages more relevant for their populations.

There are some key limitations of this study. Randomization of geographic clusters was a necessary study design adaptation. The necessity of completing randomization to identify regions in which to carry out the BCT activities before actual practice recruitment, however, meant that practice-level information, such as CVD burden in their patients, was not available at the time of randomization and could not be included in the procedure. Additionally, available resources limited the number of BCTs to 4 across the 2 states. Given the geographic and ethnic diversity of Colorado and New Mexico, this number was not sufficient to engage all key populations, such as the Native American community.

Future work will evaluate how practices used the BCT materials, how often they used which materials, and the geographic spread of the materials across all enhanced study regions. Future publications will also report on the differential impact of the enhanced

Table 3. Boot Camp Translation Participants by Boot Camp Translation Site

\begin{tabular}{|c|c|c|}
\hline $\begin{array}{l}\text { Site of BCT } \\
\text { (Region of Recruitment) }\end{array}$ & $\begin{array}{l}\text { Community Partnersl } \\
\text { Academic Participants } \\
\text { No./No. }\end{array}$ & Examples of BCT Partner Backgrounds \\
\hline Hobbs, NM (Hobbs, NM) & $12 / 2$ & $\begin{array}{l}\text { Community health workers, local pastor, county commissioner, educator, survi- } \\
\text { vors and caregivers of people with CVD, local health extension agent }\end{array}$ \\
\hline $\begin{array}{l}\text { South Valley, NM (parts of } \\
\text { Albuquerque and unincor- } \\
\text { porated Bernalillo County) }\end{array}$ & $10 / 2$ & $\begin{array}{l}\text { Community health workers, retired environmental engineer, medical assistants, } \\
\text { members of a family-run organic farm, social worker, nursing student, local } \\
\text { health extension agent }\end{array}$ \\
\hline $\begin{array}{l}\text { Greeley, CO (Northeast Colo- } \\
\text { rado region) }\end{array}$ & $11 / 3$ & $\begin{array}{l}\text { Retired teacher and farmer, reading instructor and rancher, retirees, small business } \\
\text { owner, public health professional, local practice facilitator, practice manager }\end{array}$ \\
\hline $\begin{array}{l}\text { Denver, CO (Denver and } \\
\text { Golden) }\end{array}$ & $12 / 3$ & $\begin{array}{l}\text { Community members, pastor, community health worker/Promotora, teacher, } \\
\text { retirees (retail manager, business consultant, accountant, engineer), public } \\
\text { health student, primary care clinicians, public health professionals }\end{array}$ \\
\hline
\end{tabular}


intervention as a whole, which includes both the practices' access to BCT materials and support for practices to engage patients and families in practice transformation efforts.

In conclusion, solutions to study design challenges were feasible and facilitated implementation of a community engagement method while maintaining study integrity. BCT materials from 4 different regions resulted in strong heterogeneity, suggesting that onesize-fits-all program design to help primary care practices decrease CVD risk may not be the best approach.

To read or post commentaries in response to this article, see it online at http://www.AnnFamMed.org/content/16/Suppl_1/S58.

Key words: patient engagement; community engagement; cardiovascular disease risk reduction; practice transformation; primary health care

Funding support: Publication of this article was supported by the Agency for Healthcare Research and Quality (AHRQ) through contract No. HHSA290201200019I, and grant No. R18 HS023904.

Disclaimer: This work represents the opinions of the authors and should not be interpreted as official positions of the AHRQ or the US Department of Health and Human Services.

Previous presentations: Presented at the North American Primary Care Research Group Practice-Based Research Network Conference, July 11-12, 2016, Bethesda, Maryland; and the 2016 North American Primary Care Research Group Annual Meeting, November 12-16, 2016, Colorado Springs, Colorado.

Trial registration: US trial registration number: NCT02515578.

Acknowledgments: The authors would like to thank Elizabeth W. Staton, MSTC, medical writer, for her assistance in refining this manuscript.

\section{References}

1. Institute of Medicine. Patients Charting the Course: Citizen Engagement in the Learning Health System - Workshop Summary. Washington, DC, 2011.

2. National Committee for Quality Assurance. Patient-Centered Medical Home: Recognition Programs. http://www.ncqa.org/programs/ recognition/practices/patient-centered-medical-home-pcmh. Accessed May 18, 2016.

3. Centers for Medicare $\&$ Medicaid Services. CPC+ Practice Care Delivery Requirements. https://innovation.cms.gov/Files/x/cpcpluspracticecaredlvreqs.pdf. Published 2015. Accesssed Apr 17, 2017.

4. Mosen DM, Schmittdiel J, Hibbard J, Sobel D, Remmers C, Bellows J. Is patient activation associated with outcomes of care for adults with chronic conditions? J Ambul Care Manage. 2007;30(1):21-29.

5. Tabrizi JS, Wilson AJ, O'Rourke PK. Customer quality and type 2 diabetes from the patients' perspective: a cross-sectional study. J Res Health Sci. 2010;10(2):69-76.

6. Gerber LM, Barrón Y, Mongoven J, et al. Activation among chronically ill older adults with complex medical needs: challenges to supporting effective self-management. J Ambul Care Manage. 2011; 34(3):292-303.

7. Munson GW, Wallston KA, Dittus RS, Speroff T, Roumie CL. Activation and perceived expectancies: correlations with health outcomes among veterans with inflammatory bowel disease. J Gen Intern Med. 2009;24(7):809-815.
8. Begum N, Donald M, Ozolins IZ, Dower J. Hospital admissions, emergency department utilisation and patient activation for selfmanagement among people with diabetes. Diabetes Res Clin Pract. 2011;93(2):260-267.

9. Stepleman L, Rutter MC, Hibbard J, Johns L, Wright D, Hughes M. Validation of the patient activation measure in a multiple sclerosis clinic sample and implications for care. Disabil Rehabil. 2010;32(19): 1558-1567.

10. Skolasky RL, Green AF, Scharfstein D, Boult C, Reider L, Wegener ST. Psychometric properties of the patient activation measure among multimorbid older adults. Health Serv Res. 2011;46(2): 457-478.

11. Hibbard JH, Greene J, Overton V. Patients with lower activation associated with higher costs; delivery systems should know their patients' 'scores'. Health Aff (Millwood). 2013;32(2):216-222.

12. Sharma AE, Grumbach K. Engaging patients in primary care practice transformation: theory, evidence and practice. Fam Pract. 2016.

13. Boivin A, Lehoux P, Lacombe R, Burgers J, Grol R. Involving patients in setting priorities for healthcare improvement: a cluster randomized trial. Implement Sci. 2014;9:24.

14. Westfall JM, Zittleman L, Felzien M, et al. Reinventing The Wheel Of Medical Evidence: How The Boot Camp Translation Process Is Making Gains. Health Aff (Millwood). 2016;35(4):613-618.

15. Norman N, Bennett C, Cowart S, Felzien M, Flores M, Flores R, et al. Boot camp translation: a method for building a community of solution. J Am Board Fam Med. 2013;26(3):254-63.

16. Murray D, ed. Design and Analysis of Group-Randomized Trials. New York, NY: Oxford University Press; 1998.

17. Glynn RJ, Brookhart MA, Stedman M, Avorn J, Solomon DH. Design of cluster-randomized trials of quality improvement interventions aimed at medical care providers. Med Care. 2007;45(10)(Supl 2):S38-543.

18. Campbell MK, Piaggio G, Elbourne DR, Altman DG, Group C; CONSORT Group. Consort 2010 statement: extension to cluster randomised trials. BMJ. 2012;345:e5661.

19. Ivers NM, Halperin IJ, Barnsley J, et al. Allocation techniques for balance at baseline in cluster randomized trials: a methodological review. Trials. 2012;13(1):120.

20. Westfall JM. Cold-spotting: linking primary care and public health to create communities of solution. J Am Board Fam Med. 2013;26(3): 239-40.

21. Dickinson LM, Beaty B, Fox C, Pace W, Dickinson WP, Emsermann $C$, et al. Pragmatic cluster randomized trials using covariate constrained randomization: a method for practice-based research networks (PBRNs). J Am Board Fam Med. 2015;28(5):663-72.

22. Li F, Lokhnygina Y, Murray DM, Heagerty PJ, DeLong ER. An evaluation of constrained randomization for the design and analysis of group-randomized trials. Stat Med. 2016;35(10):1565-1579.

23. United States Census Bureau. American Community Survey 5-Year Estimates. 2009-2013. https://factfinder.census.gov/faces/ tableservices/jsf/pages/productview.xhtml?pid=ACS_13_5YR_ B03002EprodType=table. Accessed Feb 14, 2017.

24. United States Department of Labor, Bureau of Labor Statistics. Local Area Unemployment Statistics (annual rate). https://www.bls. gov/lau/laucnty13.txt. Published 2013. Accessed Feb 14, 2017.

25. United States Census Bureau. Small Area Health Insurance Estimates. https://www.census.gov/library/publications/2017/demo/p3001.html. Published 2013. Accessed May 12, 2015.

26. New Mexico Health Care Workforce Committee 2014 Annual Report. http://www.nmms.org/sites/default/files/ images/2014_10_1nm_health_care_workforce_cmt_report_-_final_ print.pdf. Published 2014. Accessed Apr 17, 2017. 